Author accepted manuscript

Energy Research and Social Science

Critical Perspectives on Disruptive Innovation and Energy Transformation

Authors

Charlie Wilson, Tyndall Centre, University of East Anglia (UEA)

David Tyfield, Lancaster Environment Centre, Lancaster University

\title{
Abstract
}

What are 'disruption' and 'disruptive innovation'? And what relevance do they have for energy transformation? Ten critical perspectives offer ten contrasting responses to these questions. The relevance of Christensen's canonical definition of disruptive innovation is highly contested in its applicability to energy and climate challenges, as is the usefulness of analysing discrete business models or technologies rather than socio-technical systems. Further research on disruptive innovation and energy transformation needs to tackle: (i) the social, systemic and emissions impact of widespread adoption; (ii) how to mitigate the adverse distributional consequences of disruption; (iii) the consumer appeal of 'good enough' products for users marginalised or excluded from mainstream markets; (iv) the role of incumbents in system transformation; and ( $v$ ) the reasons for geographic variation in disruption processes currently underway. 


\section{Critical Perspectives on Disruptive Innovation and Energy Transformation}

Needs and expectations for energy system transformation keep mounting. The bar has been raised still higher by the Paris Agreement's aspirational aim for $1.5^{\circ} \mathrm{C}$ mitigation and the Sustainable Development Goals' energy access for all. Rapid, deep, and pervasive changes to the way energy is resourced, converted and used require marked discontinuity from current trends (Bataille et al. 2016, Geels et al. 2017). But does a sustainable energy future imply 'disruption'?

Innovation is conceived of most simply as novelty, or more formally, as "putting ideas into practice through an iterative process of design, testing, application, and improvement" (Wilson and Grubler 2014). Innovation is a central element in sustainable energy narratives and activities. Alongside the Paris Agreement, the G20 signed up to 'Mission Innovation' and a doubling of public R\&D investments to 'accelerate the clean energy revolution' (King 2017). Many emerging innovations - from decentralized electricity generation and electric vehicles to peer-to-peer business models and digitalisation - are frequently labelled as 'disruptive' (McKinsey 2013). But 'disruptive innovation' is a slippery term used differently by entrepreneurs, incumbents, regulators and academics, and applied variously to technologies, business models and sociotechnical systems. Shorn of its association with innovation, 'disruption' also takes on a very different and largely negative connotation.

So what are 'disruption' and 'disruptive innovation'? And what relevance do they have for energy transformation?

This Special Section on 'Disruption and Energy Transformation' offers ten Perspectives on what disruption and disruptive innovation mean, and whether they are useful lenses for examining the sustainable energy challenges of our time. The Perspectives were invited from authors with a range of backgrounds who were given free rein to articulate their views subject to two constraints: they had to explain how they interpreted the terms 'disruptive innovation' and/or 'disruption'; and they had to explore whether and how they thought either term was relevant for energy transformation. As Perspectives they are intended to be "opinion-like pieces on a 'hot' topic, introducing new concepts, ideas and findings to the field of energy studies" (ERSS Editorial Guidelines).

The collective result is an illuminating set of arguments and counterarguments, often touching on Christensen's canonical definition of disruptive innovation, but then departing in critical and often intriguing directions. Clayton Christensen, a leading business and management scholar, popularised the term 'disruptive innovation' to describe low-cost, low-end goods and services which appeal to consumers marginalised or excluded from mainstream markets (Christensen 1997). Historical examples of disruptive innovations from microcomputers to discount retailers - illustrate their transformative potential. Could analogous disruptive low-carbon innovations help transform energy systems? The perspectives in this Special Section explore this question in depth, and reach conclusions ranging from a circumspect yes to a categorical no. But it is the arguments why which are important. 
To be clear, this is not an abstract or theoretical debate. Energy transformation requires directed, aligned, multi-scale efforts to innovate more sustainable ways of producing, distributing and using energy. Consumers are an elephant in the room: at best, consumers are a neglected constituency in societal efforts to meet climate and other policy objectives; at worst, consumers are imagined as an unsurpassable barrier to sustainable transition in ways that are arguably self-fulfilling - consumption (of energy- and material-intensive goods and services) is at the heart of the problem. Yet disruptive innovation is a field of business and management scholarship specifically interested in the transformative potential of novel goods and services and their spontaneous, if surprising, adoption by consumers. Exploring the applicability of disruptive innovation to energy transformation is relevant, timely, important ... and as this Special Section reveals, highly contested.

As a first systematic attempt to apply disruptive innovation concepts to energy transformation challenges, it is not surprising this Special Section reveals ambiguous definitions, contrasting interpretations, and outright disagreements. Differences in perspective crystallise most clearly around issues of scale and scope. Are technological and business model innovations (in Christensen's mould) a useful analytical entry point? Or does the scale of the challenge require a systems perspective which rejects the primacy of discrete innovations in effecting change?

The ten Perspectives can be broadly channelled into three streams depending on how they answer these questions (Table 1).

One stream follows Christensen's arguments on novel goods and services to examine their emission-reduction potentials in consumer-facing markets (Sprei, Wilson) or in communities (Dütschke \& Wesche).

Another stream largely or wholly rejects the applicability of innovation-centred analysis of energy transformation in favour of a socio-technical systems perspective in general terms (Geels, Johnstone \& Kivaama, McDowall) or specifically in cities (Dixon et al.).

A third stream diverges like a delta beyond the innovation-focused or systems-focused dichotomy, and explores some broader aspect of disruption and energy transformation: scenarios and disruption from without (Kramer); politics and power/knowledge (Tyfield); narratives and continuity (Winskel). 
Table 1. Three streams of critical perspective on disruptive innovation and energy transformation

\begin{tabular}{|c|c|c|c|c|}
\hline & & Stream & Object of analysis & Disruption as ... \\
\hline \multirow{3}{*}{ 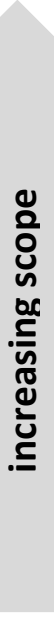 } & (3) & $\begin{array}{l}\text { and } \\
\text { beyond ... }\end{array}$ & $\begin{array}{l}\text { wider elements or implications of } \\
\text { disruption and innovation }\end{array}$ & $\begin{array}{l}\text {... as inescapably political, falsely } \\
\text { seductive, and with potentially } \\
\text { significant unintended or } \\
\text { undesirable consequences }\end{array}$ \\
\hline & (2) & $\begin{array}{l}\text { to } \\
\text { socio- } \\
\text { technical } \\
\text { systems }\end{array}$ & $\begin{array}{l}\text { interactions between niche, regime } \\
\text { and landscape levels opening up } \\
\text { (or closing down) opportunities for } \\
\text { system transition }\end{array}$ & $\begin{array}{l}\text {... as narrowly concerned with } \\
\text { minor point-source change } \\
\text { compared to reconfiguration of } \\
\text { socio-technical systems with } \\
\text { social, political, cultural and } \\
\text { infrastructural dimensions }\end{array}$ \\
\hline & (1) & $\begin{array}{l}\text { from } \\
\text { technologies } \\
\text { and business } \\
\text { models }\end{array}$ & $\begin{array}{l}\text { technologies and business models } \\
\text { offering goods and services with } \\
\text { novel attributes to consumers }\end{array}$ & $\begin{array}{l}\ldots \text { as alternatives to mainstream } \\
\text { forms of service provision and } \\
\text { incumbent service providers }\end{array}$ \\
\hline
\end{tabular}

In compiling this Special Section, we have opted not to go for the sequential organisation of the ten Perspectives into these three streams. Instead, we have ordered the Perspectives cyclically from innovations, to systems, to beyond, and then back again (Figure 1). Admittedly, few readers may read this Special Section linearly from start to finish. But we hope that this ordering may encourage you to do so for a critically engaging series of argument and counterargument. For although they were written separately and in parallel, the Perspectives undoubtedly speak to each other - in tones ranging from agreement to disagreement and 'ah, but what if you considered this'. We have not added cross-references between the Perspectives, preferring to confine our editorial comments to this introduction, and allowing dialogue and tension to emerge from the reading.

Figure 1. Order of Ten Perspectives on 'Disruptive Innovation and Energy Transformation'.

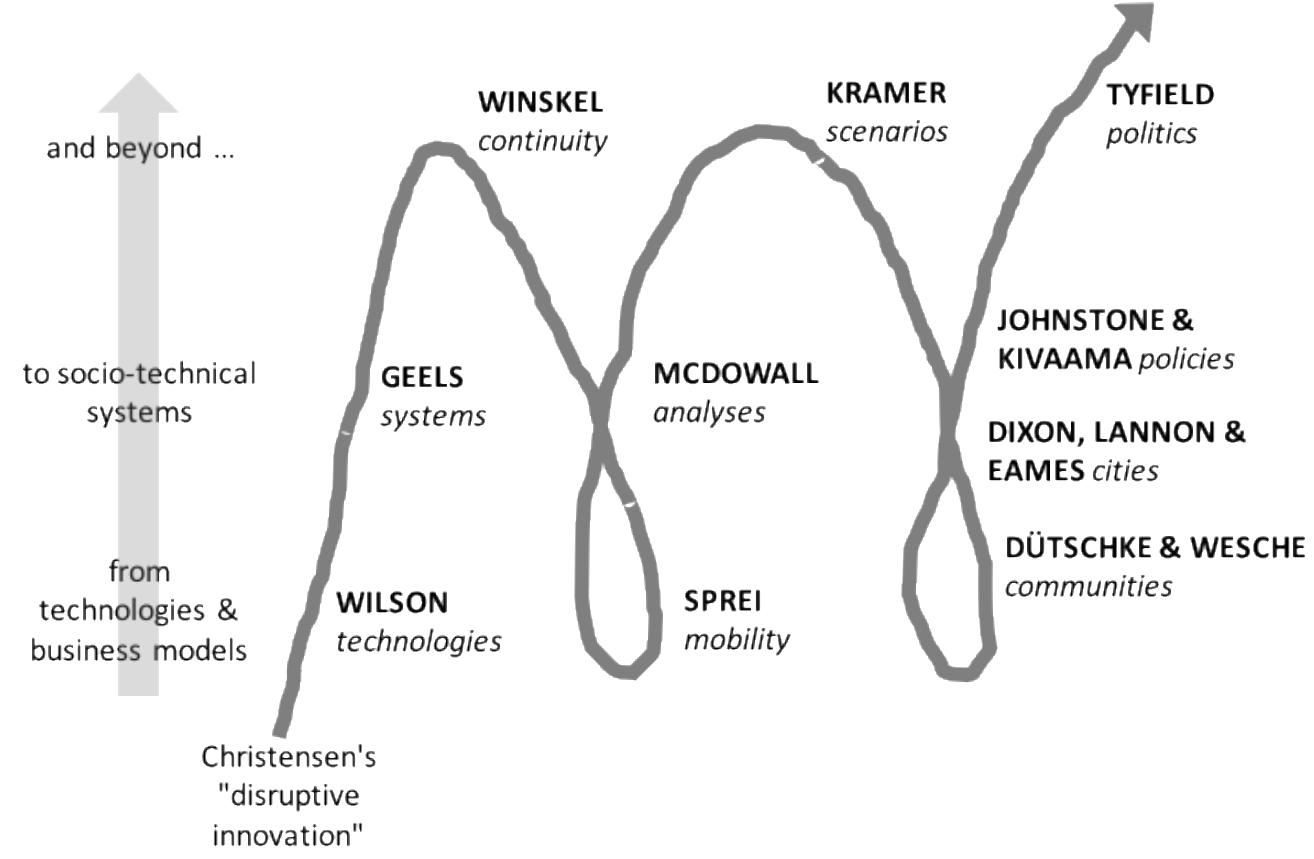


The origins of this Special Section lie in two back-to-back workshops held in London in March 2017, organised by Future Earth and the Tyndall Centre for Climate Change Research, with financial support from the UK Science \& Innovation Network. The workshops explored the potential contribution of disruptive innovation to reducing carbon emissions. The first workshop brought together low-carbon start-ups, incumbents, investors, market intermediaries, and policymakers in different domains including mobility, cities and energy supply. The second workshop brought together researchers working on low-carbon innovation and system transformation, particularly in the energy domain. Full details of the workshops are available in (Wilson 2017) or via silci.org; see also Box 1 on how to contribute to this debate.

Box 1. Express your views on disruptive innovation and energy transformation.

The two workshops mentioned in the text inaugurated an 'international forum on disruptive low carbon innovation' under the auspices of Future Earth. We would greatly welcome your ideas, thoughts or feedback on the Perspectives on this Special Section as part of this forum process. You can provide these through the SILCI project (silci.org/signup/) or through Future Earth's Open Network on Decarbonisation (via network.futureearth.org/home).

The two workshops took strikingly different perspectives on disruptive innovation and its applicability to climate change mitigation. For innovators, disruption was seen as an inherent characteristic or consequence of innovation rather than anything distinctive and worthy of specific attention. For researchers, disruptive innovation was highly contested. Neither workshop accepted wholesale the applicability of Christensen's arguments for addressing climate change. How can one of the six best business books ever written (The Economist 2011) not resonate with innovators and researchers actively working on lowcarbon innovation and system transformation?

This Special Section explores the answer in depth. Some of the authors participated in the workshops; others did not. But regardless, their brief was the same: provide an opinionated but substantiated Perspective on 'disruptive innovation and energy transformation'. Here we provide our own brief summaries of the ten Perspectives as guideposts for the reader, in order of how they appear in the Special Section.

Charlie Wilson expands on Christensen's definition of disruptive innovation, and maps it onto the challenge of reducing carbon emissions (Wilson in press). He notes that 'disruptive' and 'breakthrough' are terms often used interchangeably to describe novel technologies in breathless Silicon Valley terms, but this conflates an emphasis on users and markets (disruptive) with an emphasis on hardware and software (breakthrough). This conflation is reinforced by the results of a survey of potentially disruptive low-carbon innovations across four domains: mobility; housing \& cities; food; and energy supply \& distribution. Wilson also reports the results of a survey in which experts scored these innovations according to their potential disruptiveness and their potential impact on emissions. Numerous innovations offer both; but a deeper analysis of what low-carbon disruption means reveals many uncertainties. 
Frank Geels identifies several important limitations with Christensen's framework applied to the challenge of energy transformation (Geels in press). He argues that Christensen: is narrowly concerned with single products rather than systems with interacting innovations; focuses on market competition and so omits important social, cultural, and political influences on demand, including low-carbon energy and innovation policies; takes a 'point source' approach to change which overlooks how innovations and supposed 'heroic' innovators align with broader processes such as political struggles and societal debates. Geels goes on to explain how the multi-level perspective overcomes these limitations by offering a comprehensive account of how complex socio-technical systems change.

Mark Winskel contextualises interest in disruption within a historical trajectory of innovation scholarship from Schumpeter to the current emphasis on socio-technical transitions (Winskel in press). He notes that the disruptive entrepreneur or niche firm still play important roles in innovation systems and transition theories of change, with incumbents cast as inert, resistant, or limited to incremental change. He goes on to argue that an overblown narrative of disruption as an inherent ingredient of system transformation risks biasing analytical and policy attention away from the cumulative incrementalism or 'continuity-based dynamics' which have characterised much energysystem change to date. Recognising a continuity-based narrative for energy transformation also reconstitutes incumbents, not as an inert force to be disrupted, but as important transition actors combining new with old. Winskel considers that "by itself, the disruptive innovation narrative offers a very poor guide to research and policy".

Frances Sprei zooms in on a set of mobility-related innovations at the fringes of the current transportation system: shared mobility, mobility-as-a-service, electric vehicles, and autonomous vehicles (Sprei in press). She argues that their disruptive potential depends on consumer preferences shifting away from identity-forming and status-signalling vehicle ownership, and on the forms and modes of mobility being displaced. Car sharing may substitute for car ownership and use; or may complement it as a flexible 'second car' option. Mobility-as-a-service may move people onto public transit by weaving seamless intermodal connections; or may result in taxis substituting for active travel modes for the final legs of journeys. As a result, careful in situ studies of early adopter behaviour are urgently needed. Sprei also argues that the adoption environment for consumer-facing innovations is critically important: "regulation will be important in forming the future mobility system and ensuring innovations are disruptive in a way that actually reduces emissions and increases welfare".

Will McDowall reminds us that transformative change in markets has a long history, certainly as far back as Schumpeter's oft-invoked gales of creative destruction (McDowall in press). Against this backdrop, he argues that Christensen's contribution was to focus attention on non-users or 'low-end footholds' in the market. 'Good enough' innovations like car sharing or e-bikes could rapidly change patterns of energy service demand. McDowall argues that this potential is almost wholly ignored by systems analysts, modellers and policymakers alike. But he also makes the case that many if not most examples of lowcarbon innovation are substitutes for energy-intensive or carbon-intensive incumbents, not new goods and services for non-users. Moreover, the scale of the decarbonisation challenge requires disruption of large, interlinked energy systems comprising "networked sets of 
actors, clusters of related technology, regulatory and other institutions, and user practices". He finds that from a systems perspective, Christensen's arguments fall short.

Gert Jan Kramer takes us back to the dictionary definition of disruption as a 'serious alteration or destruction of structure' to emphasise its non-desirability (Kramer in press). Moreover, he cautions that disruption is coming one way or the other: to the economy and society from radically reducing emissions to limit warming to $1.5^{\circ} \mathrm{C}$; or to the climate system if not. Disruption and innovation are therefore awkward bedfellows which can combine in very different ways. As such, they serve as useful axes to span the scenario space for energy transformation. Kramer argues that disruptive innovation in the technical and business sense is but one eventuality. Environmental or economic disruptions forcing institutional and societal innovation are others. He also provides a hype-deflating reminder that the history of energy-system change tells us to look not for novel 'breakthrough' technologies for disrupting fossil-fuel dominance, but for long-fermenting technologies finally 'breaking through'. And even this may be limited to the electricity supply: "Once the growth of the electric renewables and all its ancillary technologies reaches its limits, the bull run of Schumpeterian innovation that we're presently witnessing will come to a natural end. And it will do so well before the Paris targets are in sight."

Elisabeth Dütschke \& Julius Wesche provide a perspective from the German Energiewende: a much-cited national-scale energy transition-in-the-making (Dütschke and Wesche in press). They focus on the role of municipalities and communities, and ask whether and how disruption affects local governance of energy service provision. From their analysis of renewable district heating systems as part of a wave of energy 'municipalisation' in Germany, they find that: "the energy transition as a broader, transnational, maybe even global process is manifesting itself ... in a disruptive way at community level". They draw attention to how the German energy transition is reshaping governance, with communities playing an ever-increasing role in planning, finance, distributing expertise, coordinating, and intermediating between heterogeneous actors.

Tim Dixon, Simon Lannon \& Malcolm Eames discuss innovative methods for identifying potentially disruptive innovations in the context of multi-scale urban retrofitting (Dixon et al. in press). Framing the challenge in socio-technical terms highlights the importance of visions, shared expectations, and roadmaps developed by multiple regime actors. A combination of participatory foresight techniques can then be used to elicit disruptive as well as sustaining innovations. Dixon and colleagues draw on the results of a major UK project examining future cities to illustrate the usefulness of these techniques, and to consider potentially disruptive innovations at building, neighbourhood and city scales.

Phil Johnstone \& Paula Kivaama argue that the multiple interpretations of disruption undermine its usefulness, and that Christensen's original conceptualisation has important limitations, ranging from its limited ex ante applicability to its 'cherry-picked' evidence base (Johnstone and Kivaama in press). Like Geels, they see disruption for energy transformation firmly through the lens of socio-technical systems. They make a forceful case for green industrial policy as an often neglected institutional mechanism for directing disruption towards social objectives such as climate change mitigation, while at the same time 
mitigating the adverse effects of disruption by supporting incumbent industries to re-skill and diversify.

Finally, David Tyfield argues that disruptive innovation is inescapably political: "To be of any relevance to low-carbon transition, what "disruptive innovation" has to disrupt is innovation(-as-politics) itself" (Tyfield in press). He critiques the disruptive label wrongly given to Silicon Valley 'Googliberalism' which serves only to reinforce the incumbency of monopolistic accumulative firms. In contrast, he illustrates how Chinese innovators of lowcost 'good-enough' products are enfranchising swathes of new consumers with goods and services previously limited to (Western) middle incomes. The emerging confluence of digital innovation with these more genuinely disruptive trends observable in China offer the most interesting scope for innovation-as-politics and energy transformation: "Low-carbon innovation is productively reframed as primarily a challenge not of emissions and energy but of data and complexity and its harnessing for productive system government." Tyfield thus provides an appropriate concluding argument for the Special Section: that disruptive innovations and socio-technical transitions are recursively linked by consumer enfranchisement destabilising incumbent forms of power.

Collectively these ten Perspectives offer a wide range of arguments and emphases with differing styles and tones. But they cohere around a sustained critical engagement with disruptive innovation and its potential for energy transformation. Nevertheless, it is a truism that research can generate more questions than it answers, and this Special Section is no exception. The ten Perspectives offer their own responses and reflections to numerous important issues on disruptive innovation and energy transformation. But cycling through the Perspectives (as illustrated in Figure 1) keeps open areas of contention and debate, and points clearly to the further research needed to reach more consensual conclusions. Here we summarise some of the key remaining questions, and also point the reader to selected Perspectives in this Special Section which offer contrasting answers.

\section{(1) Who will gain and who will lose from a disruptive transition, and how can any adverse consequences be mitigated?}

See in particular: Geels on strategies for closing down incumbents; Johnstone \& Kivaama on the potential for industrial policy to support negatively affected economic sectors; and Tyfield on the breaking up of accumulative digital capitalism and the rise of (some) nonWestern power blocs.

(2) What impact will the widespread adoption of disruptive low-carbon innovations have on emissions?

See in particular: McDowall on innovations in 'low-end market footholds'; Sprei on potentially displaced forms of mobility; and Wilson on the potential trade-off between welfare-enhancing and emissions-reducing innovations.

(3) What role do discrete technological and business model innovations play in whole system change?

See in particular: Dixon et al. on multi-scale urban retrofitting; Geels on the multi-level perspective on socio-technical transitions; Kramer on the tailing off of electricity market disruption; and Tyfield on digital innovation disrupting incumbent power structures. 
(4) What is the consumer appeal of low-end 'good enough' alternatives with the potential to displace more carbon-intensive mainstream goods and services?

See in particular: Dütschke \& Wesche on community-scale energy service provision; McDowall on new demand from non-users; Sprei on consumer preferences for ownership, identity and upfront costs; and Wilson on the attributes of disruptive low-carbon innovations.

(5) What roles do incumbents play in blocking, co-opting and driving system disruption? See in particular: Dütschke \& Wesche on municipalities in transition governance; Geels on incumbents' strategies within regime developments; Winskel on continuity-based narratives of system change and 'creative accumulation' by incumbents.

(6) In what ways can disruption and innovation interact, beyond the narrow emphasis on business and technical innovations disrupting incumbent interests?

See in particular: Johnstone on strategic policy for managing disruptive change; Kramer on environmental disruption from climate change inducing institutional and societal innovations; and Winskel on the countervailing forces of continuity-based accumulative innovation.

(7) How do the characteristics and drivers of disruptive innovation vary geographically? See in particular: Dixon et al. on urban retrofit visions and practice in the UK; Dütschke \& Wesche on the municipalisation of governance in the German Energiewende; Johnstone \& Kivaama on contrasting renewable energy experiences across Europe; and Tyfield on China as a potentially global centre of disruptive (low-carbon) innovation.

(8) What research designs and methods are best suited for studying disruptive innovation and energy transformation?

See in particular: Dixon et al. on participatory foresight techniques; Sprei on early-adopter case studies; Winskel on dynamic relationships between disruption-based and continuitybased narratives of system change; and Wilson on expert surveys.

These questions and needs for further research make clear that disruptive innovation calls for concerted empirical engagement with the full range and extent of both its actual impact and its potential impact on low-carbon transitions. The Perspectives in this Special Section show how 'disruptive' and 'innovation' are contested concepts that are developing in interactive parallel, if not necessarily converging. As we face times all but guaranteed to feature both significant disruption and innovation, this is surely set to continue. Whatever future history will show the actual and specific contribution of 'disruptive low-carbon innovations' to have been, deepening our understanding of this particular form of innovation, its impacts and measurement, promises to be particularly insightful. Working out what disruptive innovation is will constructively inform our changing understanding not only of innovation per se in this 'disruptive' context; but also of how to optimize its irreducible role in the rapid, pervasive, and accessible global system transformation that is now urgently needed. 


\section{Acknowledgements}

Charlie Wilson was supported by ERC Starting Grant \#678799 for the SILCI project (Social Influence and disruptive Low Carbon Innovation).

\section{References}

Bataille, C., H. Waisman, M. Colombier, L. Segafredo, J. Williams and F. Jotzo (2016). "The need for national deep decarbonization pathways for effective climate policy." Climate Policy 16(sup1): S7-S26.

Christensen, C. M. (1997). The Innovator's Dilemma. New York, HarperBusiness.

Dixon, T., S. Lannon and M. Eames (in press). "Reflections on Disruptive Energy Innovation in Urban Retrofitting: Methodology, practice and policy." Energy Research \& Social Science. Dütschke, E. and J. Wesche (in press). "The Energy Transformation as a Disruptive Development at Community Level." Energy Research \& Social Science.

Geels, F. W. (in press). "Disruption and Low-Carbon System Transformation: Progress and new challenges in socio-technical transitions research and the Multi-Level Perspective." Energy Research \& Social Science.

Geels, F. W., B. K. Sovacool, T. Schwanen and S. Sorrell (2017). "Sociotechnical transitions for deep decarbonization." Science 357(6357): 1242.

Johnstone, P. and P. Kivaama (in press). "Multiple dimensions of disruption, energy transitions and industrial policy." Energy Research \& Social Science.

King, D. (2017). "Global Clean Energy in 2017." Science 355(6321): 111.

Kramer, G. J. (in press). "Energy Scenarios: Exploring disruption and innovation." Energy Research \& Social Science.

McDowall, W. (in press). "Disruptive Innovation and Energy Transitions: is Christensen's theory helpful?" Energy Research \& Social Science.

McKinsey (2013). Disruptive technologies: Advances that will transform life, business, and the global economy, McKinsey Global Institute.

Sprei, F. (in press). "Disrupting Mobility." Energy Research \& Social Science.

The Economist (2011). Business books: Aiming High. The Economist. London, UK.

Tyfield, D. (in press). "Innovating Innovation: Disruptive innovation in China and the lowcarbon transition of capitalism." Energy Research \& Social Science.

Wilson, C. (2017). Disruptive Low Carbon Innovation Workshops: Synthesis Report. Norwich, UK, Tyndall Centre for Climate Change \& Future Earth.

Wilson, C. (in press). "Disruptive Low-Carbon Innovations." Energy Research \& Social

Science.

Wilson, C. and A. Grubler (2014). Energy Technology Innovation. Energy Technology Innovation: Learning from Historical Successes and Failures. A. Grubler and C. Wilson. New York, NY, Cambridge University Press: 3-10.

Winskel, M. (in press). "Energy Innovation and Systems Change: Narratives of disruption and continuity." Energy Research \& Social Science. 